\title{
A Conceptual Model for Chemical Product Design
}

\author{
Fernando P. Bernardo and Pedro M. Saraiva \\ Dept. of Chemical Engineering, GEPSI-PSE Group, CIEPQPF, University of Coimbra, Pólo II-Rua Sílvio Lima \\ 3030-790, Coimbra, Portugal
}

DOI 10.1002/aic.14681

Published online November 28, 2014 in Wiley Online Library (wileyonlinelibrary.com)

\begin{abstract}
The fundamental principles of chemical product design and associated systematic tools, within a broad domain of chemical products including molecules, formulations, and devices, are still under development. In this article, we propose a simple and fundamental conceptual model that defines the chemical product design problem as the inversion of three central design functions: quality, property, and process functions. The classic iterative cycles of product design problems may be envisioned as alternating between inversion and evaluation of these three functions, or in other words alternating between synthesis and analysis of solutions. On top of the proposed basic structure of the overall design problem, we then discuss the formulation of some subproblems as optimization problems and describe some useful solution tools. Three application examples are provided, including a more detailed case of formulation of a pharmaceutical ointment. (C) 2014 American Institute of Chemical Engineers AIChE J, 61: 802-815, 2015
\end{abstract}

Keywords: chemical product design, conceptual model, pharmaceutical formulations

\section{Introduction}

The design of chemical products, and in general of any technology-based product, can be viewed as the translation of customer needs and/or new scientific and technological findings into useful products, able to satisfy market needs and expectations. Product design is a relatively new research area within the discipline of chemical engineering, where the product manufacturing process has been the main classical scope of study. The novelty here does not refer to the discovery and development of new products that have always been there alongside with the evolution of science and society, but rather to a consistent set of principles and methods able to support the design activity as a whole, from market considerations all the way to final detailed product specifications. This structured knowledge has already been achieved in process design and with a considerable degree of success. After a promising reaction path is identified, we have fairly developed methods to guide us along the way to a full-scale optimal process, such as the hierarchy of decisions proposed by Douglas, ${ }^{1}$ the systematic generation of process alternatives based on discrete optimization, or the detailed simulation of process performance, using rigorous models and reliable numerical methods. Besides the intrinsic value of these methodologies, the maturity of process engineering is founded on a fundamental understanding of the physicochemical transformations that take place during manufacturing, including reaction, separation, and structuring operations. Based on these fundamental building blocks, and without neglecting that each one includes a variety of technologies with its particularities and difficulties, we are thus

Correspondence concerning this article should be addressed to F. Bernardo at bernardo@eq.uc.pt

(C) 2014 American Institute of Chemical Engineers able to propose a preliminary process flowsheet, using fairly established principles and models, either the process in question is for the production of simple molecules, more complex drug molecules or food formulations.

While the above statements are quite obvious for chemical engineers, in particular, for those trained in a systems view of chemical processes and related problems, we reaffirm them so as to motivate their counterpart when the goal of design moves from the manufacturing process to the product itself. The first difficulty found here is to define what we mean by a chemical product. As Cussler and Moggride did in their pioneering textbook on chemical product design, ${ }^{2}$ we consider it to be a design domain including molecules (basic or more complex), formulations (homogeneous or microstructured), and physicochemical devices (the second edition of the textbook ${ }^{3}$ covers in more detail each one of these product categories). Examples of these three classes are, respectively, a drug molecule, a pharmaceutical cream, and a transdermal patch (to deliver a drug), respectively. The question that then arises is "what concepts and methods may guide us in the conceptualization of chemical products in the large domain defined by these three classes?." The book by Cussler and Moggridge answers this big question through a four steps procedure: (1) identify customer needs and translate them into technical specifications of product performance; (2) generate ideas to meet those needs; (3) select among ideas; and (4) establish detailed product specifications and define the corresponding manufacturing process. This procedure represents a simplification over similar ones, developed for instance in the area of mechanical engineering, ${ }^{4}$ and often emphasizing the role of marketing and management in product design. Cussler and Moggridge incorporate chemical engineering topics in this basic template, namely in the translation of customer needs into product specifications, which may benefit from a processual analysis of product use, 
I. Perspective Papers. Discuss about chemical product design and engineering as an emerging opportunity for chemical engineering. ${ }^{5-13}$ Some of the topics discussed: specialty chemicals and formulations across economic sectors, what is the common denominator in the design of such variety of products, structure-properties relationships (at different scales of analysis), evolution (more than revolution) of the chemical engineering curricula to cover product issues, research challenges.

II. Textbooks. Cussler and Moggridge $(2001)^{2}$ and Wesselingh et al. $(2007)^{14}$ both essentially follow a market-pull procedure, in which chemical engineering topics are incorporated. Wei $(2007)^{15}$ presents a different perspective exploring three aspects of the design problem: the fundamental study of structure-properties relationships, what can be learned from historical cases, and the multiple facets of the design project (technical, economic, environmental and social).

III. Formulated and Structured Products. Set of papers discussing common issues in the design of formulated and structured products: products from different economic sectors (agrochemical, pharmaceutical, food), that may be categorized by physical form (solid composites, powders, gels, emulsions, foams); product properties are dependent on composition and microstructure (property function); structure modification during product use; manufacturing process based on structure creation and evolution (process function); unit operations (crystallization, compaction, grinding, mixing, emulsification, spraying); fundamentals needed (colloids, interfaces, particulate systems). Two groups of papers: (1) general aspects ${ }^{5,11,16-19}$ and (2) particular product types: agrochemicals, ${ }^{20}$ emulsions, ${ }^{21,22}$ creams and pastes, ${ }^{23}$ pharmaceutical capsules and tablets, ${ }^{24}$ and detergents. ${ }^{25}$

IV. Computer-Aided Molecular Design. Computational methods to generate and select molecules or mixtures of molecules from a set of fundamental units, and based on predictive models of physicochemical properties. ${ }^{26-28}$

and in the selection among different product concepts, where the decision criteria are often a combination of subjective and hard to quantify issues, but also objective measures based on thermodynamic and kinetic considerations.

Other important contributions to a more structured view of chemical product design have been given, a selection of which is presented in Table 1. One of the most visible facets of these publications (group I, in Table 1) is the statement that product design is an emerging opportunity for chemical engineers and that the basic curricula should be adapted and enriched to cope with the increasing number of professionals involved in product-oriented industries, although the fundamentals and methodologies to be explored are not always clear. Besides the basic design template presented by Cussler and Moggridge, other views deserve here a brief presentation.

The textbook by James $\mathrm{Wei}^{15}$ underlines the role of structure-properties relationships (designated below as property functions), mainly for the case of molecular products, reviewing theories and methods from a design perspective, in which the main problem is to find a material or product with desired properties (reverse search problem). Important historical discoveries are also explored as a means to learn about successful patterns and be aware of the multiple issues (technical, regulatory, environmental, and social) along the often tortuous path of a design project, from the initial motivation till product commercialization. The textbook by Wesselingh et al. ${ }^{14}$ roughly follows the Cussler and Moggridge's template, with some distinctive features, namely in the suggested teaching guidelines and also in the design examples, mostly of formulated products, that are presented.

$\mathrm{Ng}$ and coworkers ${ }^{5,16}$ propose step by step procedures focused on particular product families (formulated consumer products, creams and pastes, pharmaceutical capsules and tablets, and detergents), combining valuable heuristic rules, settled in those product sectors, with more fundamental relationships. These works may be included in the broader group III of publications (Table 1), which discuss common aspects in the design of formulated products, and in particular of those having a characteristic microstructure. This internal structure of the product is recognized as a central design issue, linking product and process decisions: initially created by the manufacturing process, product structure influences product functionalities, that are expressed during product use. Two central design functions then arise, the first one relating process variables with the obtained product structure (process function) and the second one connecting that struc- ture with the product's end-use properties (property function). These final properties often result from the particular conditions of the product use process, and this means that the property function should incorporate what may be called a product use function.

Another perspective of chemical product design, that has followed its own research line, tries to solve the reverse search problem with the aid of computational models to estimate materials' properties ${ }^{26-28}$ : computer-aided molecular design (CAMD). The basic methodology adopted here is often to generate molecular structures from a set of fundamental units (e.g., molecular groups) and then, based on compatible predictive models, select a small set of alternatives with properties close to the desired ones. The power of these methods is to search a wide domain based on a limited number of fundamental units. Its main limitations are related with the need for an adequate definition of such units and the availability of reliable predictive models using such units. In the case of relatively simple molecules, as solvents or refrigerants, and associated key properties, these limitations are not critical, being possible to identify promising molecules based on group contribution estimates. The extension of these systematic searches to more complex domains (e.g., larger molecules, formulations, structured products) is still an open problem, due to the difficulty in defining basic units and predicting relevant properties. Still, the generate/ select cycle is a valuable design idea, in particular when performed in a hierarchical way: we start to search in wide domains using rough estimates and then perform more refined searches in reduced domains, reserving experimental tests for final stages of product design.

The basic ideas that we will present and explore in this article are already contained in the set of contributions organized in Table 1, although sometimes not presented in a very precise or comprehensive way. Our main objective is thus exactly to settle those ideas on a conceptual model that may provide a first basic description of the design problem, its main components and its structure. Our model is essentially a block diagram linking what we call the three central design functions: quality, property, and process functions. We argue that such a conceptual model may be useful as a basis to organize information, identify important variables and relationships, and set up mathematical formulations of particular product design subproblems.

The model itself and its inherent definitions are presented in the next section of this article, together with short illustrative examples. Then, a decomposition of the property 


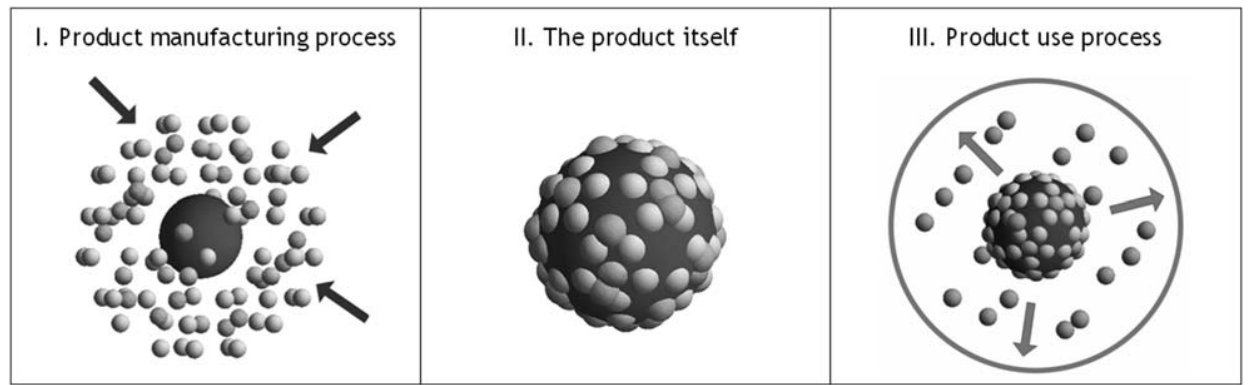

Figure 1. Symbolic representation of three key components of the product design problem.

The manufacturing process (1), driven by the inward arrows, confers a given composition and structure to the product, which then attains a given state (2); product final functionality (e.g., release of an AI) is expressed during product use (3), where external conditions, represented by the outer circumference, play an important role.

function is proposed, making the distinction between constitutive properties, more related to product composition, and operational properties, resulting from the product use in a specific environment. On top of this basic structure, we then propose basic quantitative formulations of the main design subproblems and discuss key features of those problems, stressing both routes of product synthesis and product analysis. We also discuss the formulation of some design subproblems as optimization problems and enumerate useful solution tools, covering both continuous and discrete decisions. Finally, three examples are provided, including a more detailed case of a pharmaceutical ointment that illustrates how our conceptual model may provide a useful framework to organize the product design problem as a whole and to formulate and solve particular product design subproblems.

\section{Conceptual Model}

The domain of chemical products under consideration here includes molecules, formulations, and physicochemical devices. The ultimate goal of these products is to provide certain functionalities, under a given use environment and thus satisfy customers' needs.

Product specification begins with a basic concept, which then gradually converges to a detailed definition of composition and structure. The terms composition and structure both refer to different product attributes, defined at several scales, ranging from the molecular scale to the product scale. Composition then refer to the molecular entities in a liquid mixture or the several materials that compose a discrete assembled product, and structure may correspond to the microstructure of a colloidal system or the geometrical details of a device. Besides the product itself, the design problem also includes aspects of the product manufacturing process, as for instance, the feasibility of achieving a certain microstructure under given process operating conditions.

Product performance should be equated using quantifiable and measurable indices, preferably having physicochemical meaning. Performance metrics are either constitutive properties, more directly related to product composition and structure (e.g., viscosity of a liquid mixture), or operational properties, which are the result of the product use process, and thus a more direct measure of product functionality (e.g., soil solubilization capacity of a detergent). Operational properties typically depend on constitutive properties but also on specific conditions of the product use process, which then also plays an important role in the design problem. The product use process may be seen as a downstream chemical process, in the case of an intermediate industrial product, or the product final use in a specific environment, which, in the case of foods, cosmetics, and pharmaceuticals, includes the human body. When human senses play an important role, it may be hard to define operational properties in precise physicochemical terms. In such cases, one has to rely on product sensorial assessment by users, which in general is more expensive and less accurate than physicochemical analytical techniques.

Figure 1 gives a symbolic representation of these three key components of the design problem: the product itself, its manufacturing process and its use process.

Given the above overall picture, we distinguish five product design domains, as follows:

1. Product manufacturing process-how the product is produced;

2. Product composition and structure-what the product is, at the molecular and/or supramolecular scales;

3. Product use conditions-how the product is used in a given environment and the conditions imposed by that environment;

4. Product performance-how the product performs, in terms of constitutive and/or operational properties;

5. Product quality-how the product is valued by customers, in terms of qualitative product attributes, also known as quality factors (e.g., skin feeling of a cosmetic cream, cleaning power of a detergent).

These five domains are related through three basic design functions, which constitute the backbone of our chemical product design conceptual model, as depicted in Figure 2:

1. The process function, which relates product composition and structure (pair $\left\{d_{1}, x_{1}\right\}$ ) with manufacturing process variables (design variables $d_{2}$ and operating variables $z_{2}$ ).

2. The property function, which relates product performance metrics $(p)$, with product composition and structure (pair $\left.\left\{d_{1}, x_{1}\right\}\right)$ and product use conditions $\left(z_{1}\right)$.

3 . The quality function, which relates product quality factors, directly valued by customers, with product performance metrics $(p)$, also designated as quality variables.

The block diagram of Figure 2, when read from left to right, represents the analysis of the product/process system: (1) the manufacturing process, given particular values of the design variables $d_{1}$ and $d_{2}$ and operating conditions $z_{2}$, produces a product with the state $x_{1}$; (2) this product, under 


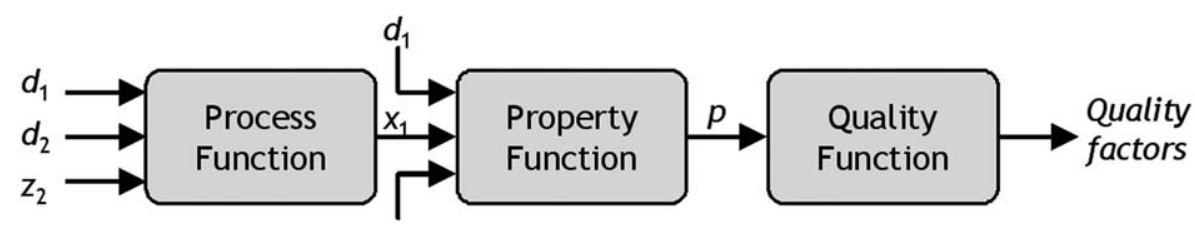

$\mathrm{z}_{1}$

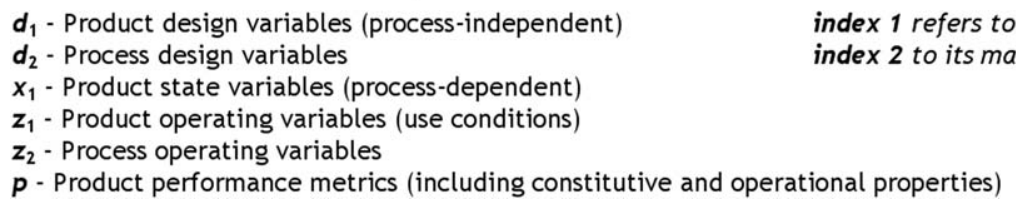

Figure 2. Conceptual model for chemical product design.

conditions $z_{1}$, has properties $p$; (3) some of these properties are performance metrics that determine product quality, in terms of quality factors directly valued by customers.

A first sketch of this model was previously presented by us and our collaborators, ${ }^{6,29,30}$ being now refined and simplified. Cisternas ${ }^{31,32}$ also proposed a fundamental description of the chemical product design problem that shares several aspects with our model, namely that the product is a system depending on a set of components, their organization (structure) and a specific interaction with the environment. In other words, this is our property function, with the performance $p$ being a function of the sets of variables $d_{1}, x_{1}$, and $z_{1}$.

A distinctive and important feature of our model is the distinction between process-independent variables $d_{1}$ and process-dependent variables $x_{1}$. These two sets must not be confused with product composition and product structure variables. If the process confers structure to the product but does not alter its global composition, such as in the production of a structured formulation from individual ingredients, then set $d_{1}$ includes that ingredients and their global proportion and $x_{1}$ represents product structural attributes (e.g., emulsion microstructure). However, if the process determines both product composition and structure, then set $x_{1}$ includes both types of variables. For instance, in the production of a crystalline solid, both purity and crystal size are processdependent variables. Table 2 clarifies the meaning of all variable sets using three simple examples, corresponding to basic product/process typologies.

\section{The property function for product operational properties}

In the case of operational properties, the property function may be decomposed into constitutive models, describing more fundamental properties of the materials from which the product is made, and product use models, describing physicochemical processes that take place during product use (Figure 3 ). These processes depend on properties of the materials that make up the product (constitutive properties $\theta_{1}$ ), and also on characteristic materials and conditions of the surrounding environment or resulting from the specific product/environment interaction (parameters $\theta_{3}$; index 3 refers to the surroundings). In the example given in Figure 3 (pharmaceutical ointment applied on skin), a key process is the transport of the drug molecule from the ointment to the skin and then across several skin layers. The drug diffusion coefficient across the ointment layer is an example of a constitutive parameter $\theta_{1}$ and the mass-transfer resistances of the several skin layers are important parameters within the set $\theta_{3}$.

The product/environment interaction may function in both ways: product composition and structure may change during product use and, conversely, product use may induce alterations in the surrounding environment. An example of the first case is the change in the ointment microstrucutre after application on skin, such as partial destabilization of

Table 2. Illustration of Variable Sets in the Proposed Conceptual Model (Figure 2) for Different Product/Process Typologies

\begin{tabular}{|c|c|c|c|}
\hline & \multicolumn{3}{|c|}{ Product/Process Typology } \\
\hline & $\begin{array}{l}\text { Liquid mixture/trivial } \\
\text { mixing process }\end{array}$ & $\begin{array}{l}\text { Structured formulation/process } \\
\text { affects product structure } \\
\text { but not its global composition }\end{array}$ & $\begin{array}{l}\text { Structured formulation/process } \\
\text { affects product composition } \\
\text { and structure }\end{array}$ \\
\hline Product Example & Perfume & Cosmetic emulsion & $\begin{array}{l}\text { Microcapsules containing a drug solution } \\
\text { enclosed by a polymeric wall }\end{array}$ \\
\hline$d_{1}$ & $\begin{array}{l}\text { Individual components } \\
\text { and their proportion }\end{array}$ & $\begin{array}{l}\text { Individual components } \\
\text { and their proportion }\end{array}$ & Drug, solvent, polymer \\
\hline$d_{2}$ & $\begin{array}{l}\text { Process configuration and } \\
\text { equipment design }\end{array}$ & & \\
\hline$x_{1}$ & $\begin{array}{l}\text { Empty set, since product state is } \\
\text { process-independent (assuming } \\
\text { negligible losses during processing) }\end{array}$ & Droplet size & $\begin{array}{l}\text { Capsule size, wall thickness, drug } \\
\text { concentration inside capsule }\end{array}$ \\
\hline$z_{2}$ & $\begin{array}{l}\text { Process degrees of freedom } \\
\text { and input conditions }\end{array}$ & & \\
\hline$z_{1}$ & $\begin{array}{l}\text { Conditions affecting fragrance } \\
\text { evaporation } \\
\text { and dispersion }\end{array}$ & $\begin{array}{l}\text { Shear stress during } \\
\text { application on skin }\end{array}$ & $\begin{array}{l}\text { External conditions affecting } \\
\text { drug release }\end{array}$ \\
\hline$p$ & $\begin{array}{l}\text { Concentration of fragrances } \\
\text { in inhaled air }\end{array}$ & $\begin{array}{l}\text { Emulsion rheology during } \\
\text { application on skin }\end{array}$ & Rate of drug release from the capsule \\
\hline Quality factor & Perceived odour & Skin feeling & Controlled drug delivery and effects thereafter \\
\hline
\end{tabular}




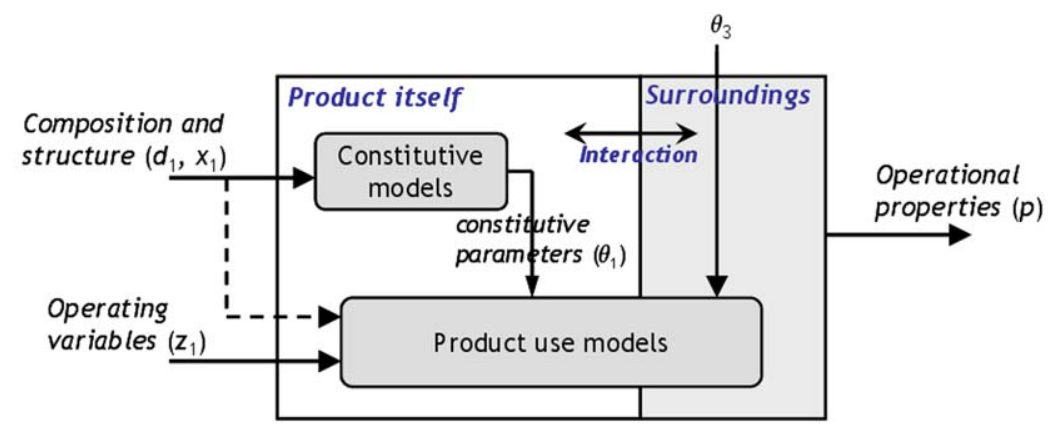

\begin{abstract}
Example of an emulsion-type pharmaceutical ointment for systemic drug absorption $\boldsymbol{d}_{1}$ - drug + excipients and corresponding mass fractions.

$x_{1}$ - droplet size

$\mathbf{z}_{1}$ - ointment volume applied on skin, area of application, patient blood volume, time between consecutive applications.

$\theta_{1}$ - drug partition coefficient between dispersed and continuous phases of the ointment, diffusion

coefficient in continous phase, partition coefficient between skin outer layer and continuous phase,...

Product use model: mass transfer model describing transdermal drug delivery from the emulsion vehicle.

$\theta_{3}$ - mass transfer resistance of the several skin layers, drug pharmacokinetic parameters.

p - temporal profile of drug concentration in plasma, mean deviation of this profile from a target value.
\end{abstract}

Figure 3. Structure of the property function, in the case of operational properties, and exemplification of variable and parameter sets with the case of a pharmaceutical ointment.

[Color figure can be viewed in the online issue, which is available at wileyonlinelibrary.com.]

droplets. Interaction in the reverse way occurs when the ointment is formulated with permeation enhancers, which are specific molecules that interact with skin lipids, disordering them and thus enhancing drug diffusion through skin. ${ }^{33}$

With this description of the property function, the product/ process design problem may be viewed as the design of two processes in series, from which final product performance results: the product manufacturing process, upstream of the product itself, and the product use process, downstream, this last one incorporating material-properties relationships (constitutive models). This perspective therefore stresses the importance of traditional chemical process engineering in the design of new chemical products.

\section{Basic formulation of product design problems}

The process function may be implicitly represented by the set of equations

$$
f_{2}\left(d_{1}, d_{2}, z_{2}, x_{1}\right)=0
$$

The number of equations is $n_{2}=\operatorname{dim}\left(x_{1}\right)$ and $x_{1}$ is a set of dependent variables. In a similar manner, the property function is stated as $n_{1}=\operatorname{dim}(p)$ equations

$$
f_{1}\left(d_{1}, x_{1}, z_{1}, p\right)=0
$$

Using the decomposition of Figure 3 above, one has:

1. Constitutive models defined by $n_{1 \mathrm{c}}=\operatorname{dim}\left(\theta_{1}\right)$ equations

$$
f_{1 \mathrm{c}}\left(d_{1}, x_{1}, \theta_{1}\right)=0
$$

2. Product use models defined by $n_{1}$ equations

$$
f_{1 \mathrm{u}}\left(d_{1}, x_{1}, z_{1}, \theta_{1}, \theta_{3}, p\right)=0
$$

Equations 4 and 2 are equivalent forms of the property function.

Both representations (1) and (2) are here given in a generic form, without making distinction between algebraic and differential equations or between continuous and discrete variables. Set $d_{1}$, for instance, may include binary decisions relative to the presence of a particular chemical species in a formulation and the set $f_{2}$ may include differential equations modeling the temporal evolution of a particular process step. Also, intermediate state variables are not specified: in the process function (1), these may refer to intermediate product states during processing, while the property function (2) may involve primary material properties $\theta_{1}$ affecting the final property of interest $p$. Globally, once the degrees of freedom $d_{1}, d_{2}, z_{1}$, and $z_{2}$ are specified, the model (1) $+(2)$ may be solved to predict product properties $p$.

The quality function does not have a complete quantitative description, as quality factors (or customer needs) are by definition qualitative propositions stating product attributes as valued by customers. These attributes must first be translated into objective product performance specifications of the type $p \sim p^{*}$, where $p^{*}$ are target values for the performance metrics $p$. In some cases, this translation of customer needs into quantitative specifications is fairly well understood, such as for industrial products with well defined target performance (e.g., solvents, surfactants, and flocculants) or in the case of common attributes of consumer products (e.g., consistency of semisolid products, related to rheologial properties; shelf life, usually determined by fairly understood physical and/or (bio)chemical deterioration processes). More difficult situations are often related to human sensorial attributes that are hard to define in physicochemical terms, such as "smoothness of a cosmetic cream" or "mouthfeel of a food product." these cases, one ultimately relies on sensorial panel tests, where product samples are directly evaluated by users in terms of a sensorial performance index $p$, often defined in an arbitrary scale (e.g., appraisal from 1, unsatisfactory, to 5, very good). As a general rule, this kind of assessment should be viewed as a last resort, since product assessment in terms of physicochemical properties, measurable in the laboratory, is often cheaper, faster and easier to apply in earlier stages of conceptual and exploratory product design.

Once quality factors are effectively translated into a set of performance metrics, a quantitative treatment of the quality function is relatively simple. For each performance metric $p$, one may define rigid restrictions of the type $|p-p *| \leq \delta$ with $\delta$ being a given tolerance, or having the more general form 
Table 3. General Characteristics of the Three Central Design Problems

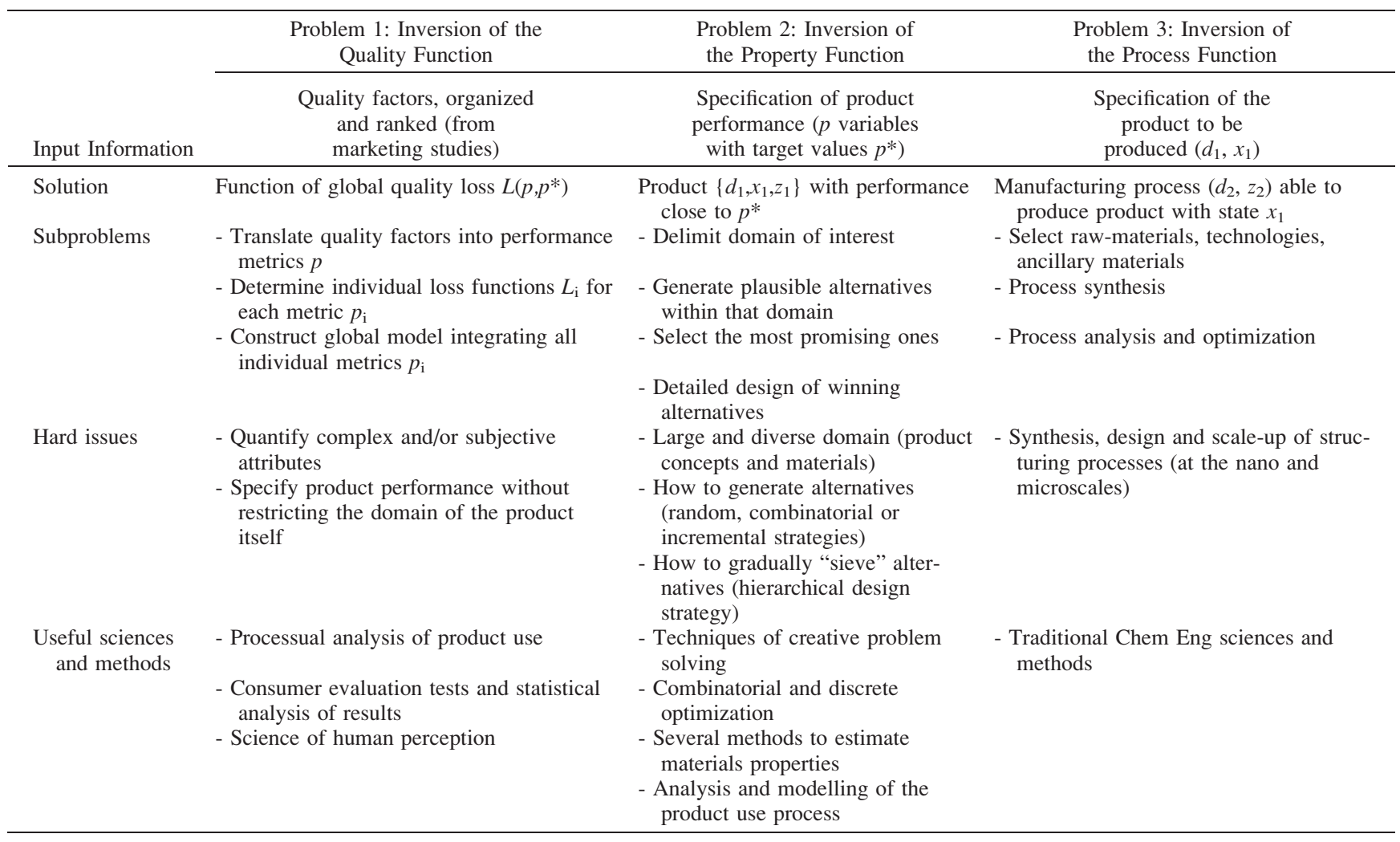

$g\left(p, p^{*}\right) \leq 0$. In alternative, a continuous perspective of quality loss may de adopted, using Taguchi loss functions that usually have a quadratic form: loss $L$ equals to $k\left(p-p^{*}\right)^{2}$, where $k$ is a loss coefficient, estimated from customer satisfaction data. ${ }^{35}$ Ultimately, a global loss function $L\left(p, p^{*}\right)$ may be constructed (or a complementary function of customer satisfaction), integrating individual metrics $p_{\mathrm{i}}$ using for instance a weighted sum. The weights attributed to each quality factor must be determined from carefully designed customer tests. ${ }^{36,37}$

Back to Figure 2, we can now read it from right to left, which is the natural design route, and thus formulate the product design problem as a series of the following three subproblems:

Problem 1. Translate product quality factors, as valued by customers, into a set of product performance metrics $p$, preferably with physicochemical meaning. Then, quantify desired product performance using restrictions of the type $g\left(p, p^{*}\right) \leq 0$, or associated loss functions $L\left(p, p^{*}\right)$.

Problem 2. Given the above quantitative models and restrictions for product quality, find $\left\{d_{1}, x_{1}\right\}$ (and eventually a subset of $\left.z_{1}\right)$ such that $f_{1}\left(d_{1}, x_{1}, z_{1}, p\right)=0$. This is called the inverse search problem or the inversion of the property function, which aims to find a material or product with prespecified properties.

Problem 3. Find $\left\{d_{2}, z_{2}\right\}$ such that $f_{2}\left(d_{1}, d_{2}, z_{2}, x_{1}\right)=0$. This is the classical process design problem, whose goal is to specify a manufacturing process able to produce product state $x_{1}$.

In short, these three problems may be simply stated as the inversion of the quality, the property and the process functions, as depicted in Figure 2 when read from right to left. A detailed discussion of each of them and corresponding useful methods of solution falls outside the scope of this article, although a useful processual view of problem 2 was given in the previous section, and also a summary of key aspects is summarized in Table 3. As may be seen from this table, a diverse blend of sciences and methods may be required, usually going beyond traditional chemical engineering domains. Regarding problem 2, it should be stressed that the initial domain of interest may be quite large and embrace very diverse alternatives, as in an early design stage we are seeking for basic product concepts and associated technologies, able to provide funcionalities $p$, while materials to be used and other product details are still unknown.

Overall, and except for routine simple cases, the solution of problems 1, 2, and 3 does not proceed as a linear sequence. After a first product performance specification and a first generation/selection of product concepts, one often has to refine the analysis of selected alternatives and thus, referring to Figure 2, proceed from left to right. Specifications $p^{*}$ are then revised and a new, more focused, design route (from right to left) is initiated. These alternate routes in opposite directions-synthesis/analysis cycles-are repeated until a satisfactory solution is attained, subject to time and budget limitations.

In the next section, basic optimization formulations of these design problems will be presented. While clearly useful in final design stages, when quantitative models are constructed, we argue that such formulations are also useful in previous and more exploratory design stages, as a basis to organize large and diverse data and to identify key design subproblems, variables, and decisions.

\section{Optimization-based formulations and associated tools}

Given the above representations for the process function, Eq. 1, and the property function, Eq. 2, and a quantitative 
model of product quality [restrictions $g\left(p, p^{*}\right) \leq 0$ and/or global loss function $\left.L\left(p, p^{*}\right)\right]$, it is simple to write a mathematical formulation for optimal product/process design, at a higher level of abstraction. Let $F$ be a global objective function to be maximized, necessarily including the loss of quality $L$ and the manufacturing process costs. The optimization problem is then

$\max _{d_{1}, d_{2}, z_{1}, z_{2}} F\left(d_{1}, d_{2}, z_{1}, z_{2}, p, p *\right)$ [global produt/process performance]

s.t. $f_{1}\left(d_{1}, x_{1}, z_{1}, p\right)=0 \quad$ [property function]

$f_{2}\left(d_{1}, d_{2}, z_{2}, x_{1}\right)=0 \quad$ [process function]

$g(p, p *) \leq 0 \quad$ [product performance restrictions]

$h\left(d_{1}, d_{2}, z_{1}, z_{2}, x_{1}\right) \leq 0 \quad$ [other restrictions]

The design degrees of freedom are here the sets $d_{1}, d_{2}, z_{1}$, and $z_{2}$, i.e. product and process design and operating variables.

If product and process design problems are decoupled, one obtains a sequence of two problems. First, the product design problem, without considering limitations imposed by the process function

$$
\begin{array}{ll}
\max _{d_{1}, x_{1}, z_{1}} & F_{1}\left(d_{1}, x_{1}, z_{1}, p, p *\right) \quad \text { [product performance] } \\
\text { s.t. } & f_{1}\left(d_{1}, x_{1}, z_{1}, p\right)=0 \quad \text { [property function] } \\
& g(p, p *) \leq 0 \quad \text { [product performance restrictions] } \\
& h\left(d_{1}, x_{1}, z_{1}\right) \leq 0 \quad \text { [other restrictions] }
\end{array}
$$

This problem results on the optimal product $\left\{d_{1} *, x_{1} *, z_{1} *\right\}$, for which one then looks for an optimal manufacturing process

$$
\begin{array}{ll}
\max _{d_{2}, z_{2}} & F_{2}\left(d_{2}, z_{2}\right) \quad \text { [process performance] } \\
\text { s.t. } & f_{2}\left(d_{1}^{*}, d_{2}, z_{2}, x_{1}^{*}\right)=0 \quad \text { [process function] } \\
& h\left(d_{2}, z_{2}\right) \leq 0 \quad \text { [other restrictions] }
\end{array}
$$

The concretization of these formulations in practice poses two main difficulties, particularly in early design stages. First, when alternative basic product concepts and principles of functioning are still being explored, a comprehensive definition of the search domain $\left\{d_{1}, x_{1}, z_{1}\right\}$ is still lacking and thus systematic searches are hard to perform. Second, even when the design domain is clear, quantitative property functions may be very hard to construct. In the development of a dermal product, for instance, the initial stages may be open to several physical forms of the product, including paste, cream, lotion, gel, spray, or patch. This set of physical systems corresponds to a large and diverse physicochemical domain $\left\{d_{1}, x_{1}, z_{1}\right\}$, difficult to enumerate and even more difficult to explore in a systematic and efficient way. The analogous problem in process design is to choose basic technologies, unit operations and their arrangement. In this case, however, there are more developed tools to describe basic processing units, in particular for fluid-phase processing, and thus formulate and solve problem (7) with a systematic search within the domain $\left\{d_{2}, \mathrm{z}_{2}\right\}$. ${ }^{38}$

For relatively simple molecules with well-defined target performance (e.g., solvents for liquid-liquid extraction), a systematic approach is possible if property functions can be equated based on a finite number of fundamental units, whose different combinations produce alternative molecules. If those fundamental units are molecular groups, then the property functions are group contribution methods, already developed in different domains (solvents, polymers, and even more complex molecules). The design problem then reduces to find combinations of those fragments that produce molecules with good performance, which may be formulated as a discrete optimization problem. This is a particular case of problem (6) for which the design variables $d_{1}$ are the number of fragments of the type $k$ in the molecule (integer variables), with $k=1, \ldots, K$ and $K$ being the number of fundamental units considered. In the Chemical Engineering literature, this approach to molecular design is known as CAMD,${ }^{26}$ although in rigor this designation includes other less systematic strategies, often more dependent on trial and error.

The extension of CAMD to fluid-phase mixtures is in principle simple, with the set $d_{1}$ now including molar fractions of the several species in the mixture (continuous variables). Naturally, one here needs reasonable models to estimate mixture properties. A still open problem is the extension of CAMD methods to more complex formulations, including those where nano or microscales are important. Here, besides molecular species and their concentration, design variables $\left\{d_{1}, x_{1}\right\}$ need to include a representation of the several possible microstructural attributes, such as size and shape of dispersed phases, or thickness of a nanolayer. Further, one then needs to estimate how composition and structure affect key product properties, which clearly may be hard to accomplish even in relatively narrow product domains. We believe that an effective approach to this problem should begin with the definition of tractable product subdomains of interest (e.g., o/w emulsions with thickened aqueous phase) and incorporation of specific heuristic knowledge from corresponding industrial sectors, including qualitative rules of the type: "ingredients A and B must go together", "property $p$ increases with A", or "if property $p$ is desired than $x$ must be greater than $x^{*}$ ". ${ }^{16,24}$

In some cases, another decomposition of problem (5) may be quite useful. ${ }^{39}$ When operational properties may be equated independently of $\left\{d_{1}, x_{1}\right\}$ (structure of Figure 3 without dashed arrow), problem (5) may be decomposed into two subproblems. First, we find constitutive properties $\theta_{1}$ and use conditions $z_{1}$ corresponding to the desired functionality (here restrictions $h(\cdot) \leq 0$ are omitted)

$$
\begin{array}{ll}
\max _{z_{1}, \theta_{1}} & F_{1}\left(z_{1}, p, p *\right) \quad \text { [produt performance] } \\
\text { s.t. } & f_{1 u}\left(z_{1}, \theta_{1}, \theta_{3}, p\right)=0 \quad \text { [product use models] } \\
& g(p, p *) \leq 0 \quad \text { [product performance restrictions] }
\end{array}
$$

Then, we look for a product composition and structure $\left\{d_{1}, x_{1}\right\}$ matching those constitutive properties. If $\theta_{1} *$ is the solution of the first problem, and using a quadratic deviation criterion, the second problem becomes

$$
\begin{aligned}
& \min _{d_{1}, x_{1}}\left(\theta_{1}-\theta_{1}^{*}\right)^{T}\left(\theta_{1}-\theta_{1}^{*}\right) \\
& \text { s.t. } f_{1 c}\left(d_{1}, x_{1}, \theta_{1}\right)=0 \quad \text { [constitutive models] }
\end{aligned}
$$

This strategy is of direct application in the case of industrial products whose performance may be equated without 
specifying their molecular composition (e.g., solvents, antisolvents, and refrigerants). For instance, in the design of a solvent for liquid-liquid extraction, one may first determine what should be the solvent solubility properties $\theta_{1}$ to attain a given extraction efficiency $p^{*}$, and without specifying the solvent molecule-problem (8). Then, in a second stage, we look for a molecule or mixture of molecules having those solubility properties-problem (9). The search for a solution $\left\{d_{1}, x_{1}\right\}$ is thus facilitated through the intermediate guiding variables $\theta_{1}$. A two-stage approach of this type has not yet been formally developed for more complex formulated products and respective use processes. In the ointment example of Figure 3, and supposing that the drug molecule is already chosen, such an approach corresponds to first determine what should be the drug equilibrium and kinetic parameters to attain a target plasma concentration, and only after that to choose an adequate ointment microstructure and composition.

We finish this section with a brief reference to useful mathematical tools to formulate and solve the above stated optimization problems.

Mixed-integer optimization, as already mentioned, is the fundamental tool to handle large discrete domains, such as combinations of molecular fragments into a molecule or of molecules into a formulation. Problems are often nonlinear and thus one should have available state-of-the-art solvers, including those with global optimization algorithms. ${ }^{40}$

Due to model uncertainties, more than a single solution, which is optimal only in a strict mathematical sense, we want to find a small set of promising solutions for further investigation, namely experimental testing. ${ }^{41}$ In problems with integer decisions, a set of the first $S$ best solutions may be obtained using integer-cuts. ${ }^{42}$ Also, some global solvers provide not only the global solution but also the best $S$ solutions found along the performed search, with $S$ being an input specified by the user (e.g., BARON solver ${ }^{40}$ ).

Product/process design problems are often multiobjective optimization problems, where for instance cost, performance and risk have to be handled together. A straightforward approach to conciliate several objectives [as implicitly considered in formulation (5)] is to define a global cost or performance function integrating those objectives under a common basis (usually a monetary basis). However, if it is not possible to define in rigor such a global objective and/or if the decision maker requires detailed and separated information regarding two (or more) objectives, these should be handled separately and nondominated solutions (Pareto solutions) should be calculated. In a product/process integrated problem like (5), the two separated objectives under analysis may be product performance $F_{1}$, on one hand, and production costs $C_{2}$, on the other hand. In this case, the classical Pareto curve of performance vs. cost may be obtained solving the problem "maximize $F_{1}$, subject to $C_{2} \leq \alpha$," for increasing values of $\alpha$.

Optimization under uncertainty tools are also useful to calculate robust solutions, able to cope with variability in input conditions, and to better rationalize decisions in face of actual uncertainty levels in different problem components and design stages. ${ }^{43,44}$ Such tools may also be used to evaluate the value associated with acquiring additional information regarding particular problem components (value of information analysis), thus providing a quantitative basis to guide further R\&D efforts. ${ }^{45,46}$

\section{Examples}

Three examples are here provided. In the first two-liquid perfumes and a cosmetic emulsion-the main goal is to illustrate how design variables and relationships are organized accordingly to our conceptual model. The third example-formulation of a pharmaceutical ointment-is more detailed and tries to illustrate the use of our conceptual model as a base to organize a large set of information, to guide and structure the design process and to setup optimization formulations of particular subproblems.

\section{Liquid perfumes}

The performance of a liquid perfume may be described in terms of four quality factors, all related to fragrance perception at different conditions: impact (efficacy of the fragrance during the first instants after application), diffusion (refers to the distance over which the fragrance is perceived soon after application), tenacity (long-term efficacy), and volume (refers to the distance over which the fragrance is noticed some time after application). A simple model of perception is one based on the odor value $(\mathrm{OV})$, which is the ratio between the effective concentration of a given fragrance $i$ in the air $\left(C_{\mathrm{i}}\right)$ and a threshold value $\left(\mathrm{Th}_{\mathrm{i}}\right)$ above which the fragrance is perceived by humans (determined from standard perception tests) ${ }^{47}$

$$
\mathrm{OV}_{\mathrm{i}}=\frac{C_{\mathrm{i}}}{\mathrm{Th}_{\mathrm{i}}}
$$

The perception model then states that the fragrance more strongly perceived by the human nose is the one having the highest OV. For a liquid perfume with components $i$, $i=1, \ldots, N$, including fragrances, solvents, and eventually other auxiliary substances, the perceived component is then component $i^{*}$, such that

$$
i *=\underset{\mathrm{i}}{\arg \max }\left(\mathrm{OV}_{\mathrm{i}}\right)
$$

The OV may be defined as a function of time $t$ after perfume application and distance $z$ from source. The corresponding perceived substance is thus $i^{*}(t, z)$. This function is an important component of the quality function, relating objective performance metrics $\left(\mathrm{OV}_{\mathrm{i}}\right)$ with a product characteristic directly perceived by consumers (perceived fragrance $\left.i^{*}\right)$. It is then useful to translate the four quality factors above into quantitative specifications. For instance, a perfume with a initial impact of fragrance $\mathrm{A}$ and a tenacity of fragrance $\mathrm{C}$ over distance $z_{\mathrm{C}}$ may be specified as: $i^{*}(t, z)=\mathrm{A}$, for low $t$ and low $z$, and $i *(t, z)=\mathrm{C}$ for high $t$ and $z<z_{\mathrm{C}}$.

Moving now to the property function, we need to relate the performance metrics $\mathrm{OV}_{\mathrm{i}}$ with the liquid perfume composition and use conditions. Maximum values of $C_{\mathrm{i}}$ and $\mathrm{OV}_{\mathrm{i}}$ are attained close to the liquid/air interface and may be estimated through a vapor-liquid equilibrium model

$$
\mathrm{OV}_{\max , \mathrm{i}}=\gamma_{\mathrm{i}} x_{\mathrm{i}} \frac{p_{\mathrm{i}}^{*} M_{\mathrm{i}}}{\operatorname{Th}_{\mathrm{i}}} \frac{1}{R T}
$$

Here, $x_{\mathrm{i}}$ is the molar fraction in the liquid phase, $\gamma_{\mathrm{i}}$ the activity coefficient in the liquid phase, $p_{\mathrm{i}}^{*}$ the vapor pressure of pure $i, M_{\mathrm{i}}$ the molar mass, $T$ the temperature, and $R$ the ideal gas constant. Actual values of $\mathrm{OV}_{\mathrm{i}}(t, z)$ may be estimated with a transient model of fragrances evaporation and subsequent transport in the gas phase. If only maximum 
values of $\mathrm{OV}$ are considered, Eq. 12 is already the desired property function, where

- Product design variables $d_{1}$ are components $i$ and their molar fractions $x_{\mathrm{i}}$ in the liquid;

- The only product use variable $z_{1}$ is the temperature of use $T$;

- Parameters $\gamma_{\mathrm{i}}, p_{\mathrm{i}}^{*}, M_{\mathrm{i}}$, and $T h_{\mathrm{i}}$ depend on the above variables.

The process function is in this case irrelevant as the perfume is made by a trivial mixing process. If evaporation losses are negligible, then molar fractions $x_{i}$ remain constant during processing and thus belong to the set of processindependent design variables $d_{1}$. The set of processdependent state variables $x_{1}$ is then empty.

\section{A cosmetic emulsion}

A moisturizing lotion is an oil-in-water emulsion with 10 $20 \%$ of occlusive and emollient oils, and a thickened aqueous phase. Here, we only focus on two quality factors: the so-called skin feeling, which refers to the sensations experienced during lotion application on skin, and the perceived smoothness of the emulsion. ${ }^{29}$

Sensorial tests indicate that customer evaluation of skin feeling has a strong correlation with lotion viscosity. More precisely, the ideal product should have an initial viscosity $\mu_{1}$ of around $400 \mathrm{~Pa} . \mathrm{s}$, corresponding to low applied stresses, and a much lower final viscosity $\mu_{2}$ of around 0.02 Pa.s, when the product is spread over large areas and subject to much higher stresses (the emulsion has a strong shearthinning behavior). This translation of a good skin feeling into ideal viscosity values is the chore of the corresponding quality function. For optimization purposes, it is convenient to translate the full set of sensorial data into quadratic loss functions $L_{1}$ and $L_{2}$, centered around the corresponding ideal values $\mu_{1}^{*}$ and $\mu_{2}{ }^{*}$, for which the loss is zero.

Regarding emulsion smoothness, it is known to be primarily related to the size of the dispersed phase, with emulsions having smaller droplets being perceived as smoother. The mean droplet diameter $L_{\mathrm{d}}$ is then chosen as a performance metric with a maximum admissible value of around $20 \mu \mathrm{m}$. Note that $L_{\mathrm{d}}$ also belongs to the set $x_{1}$ of product state variables, since it clearly depends on the emulsification conditions. Therefore, the property function regarding smoothness is not defined.

Back to skin feeling, we need to construct a property function relating lotion viscosity with its composition and microstructure. A base formulation is first considered, with a typical composition for the oil phase and an aqueous phase containing glycerine as a humectant agent and xanthan gum as thickener. Conciliating available experimental data for xanthan gum aqueous solutions with a plausible hypothesis to account for glycerine contribution and also a theoretical model to predict emulsion viscosity (from individual singlephase viscosities), a global model to estimate the emulsion viscosity $\mu$ is obtained, with the following input-output format

$$
\mu=f\left(w_{\mathrm{T}}, w_{\mathrm{G}}, \phi, \dot{\gamma}\right)
$$

Here, $w_{\mathrm{T}}$ is the mass fraction of thickener, $w_{\mathrm{G}}$ the mass fraction of glycerine, $\phi$ the volume fraction of oil phase, and $\dot{\gamma}$ the shear rate corresponding to the conditions of emulsion application on skin. This model is a property function with
$w_{\mathrm{T}}, w_{\mathrm{G}}$, and $\phi$ being design variables $d_{1}$ and $\dot{\gamma}$ a product use variable $z_{1}$.

To study how product and process decisions interact, a process function is needed, relating the product state variable $L_{\mathrm{d}}$ with product design variables $w_{\mathrm{T}}, w_{\mathrm{G}}$, and $\phi$, and process design and operating variables. Based on a standard batch process including mixing, heating, cooling, and emulsification operations, a process function with the following structure is developed

$$
\left\{x_{1}, x_{2}\right\}=f\left(d_{1}, d_{2}, z_{2}\right)
$$

where:

- Product design variables $d_{1}$ are $w_{\mathrm{T}}, w_{\mathrm{G}}$, and $\phi$;

- Process design variables $d_{2}$ are annual production, batch size, and equipment dimensions;

- Process operating variables are operating temperatures and speed of mixing equipment;

- The only state variable $x_{1}$ is the mean droplet diameter $L_{\mathrm{d}}$

- The set $x_{2}$ designates process state variables, including operating times, cycle time and results from mass and energy balances.

Based on the property function (13) and process function (14), one may formulate the integrated problem of optimal product and process design as follows [in agreement with the general formulation (5)]: given the annual production required, find $w_{\mathrm{T}}, w_{\mathrm{G}}, f$, and process decisions $d_{2}$ that minimise an overall annual cost, equal to the sum of investment, production, and quality loss costs. The design solution thus obtained may be superior to the one obtained following a decoupled sequential approach: optimal product design [problem (6)], followed by optimal process design [problem (7)].

\section{Formulation of a pharmaceutical ointment}

The ointment to be formulated is for application on skin and for systemic delivery of a given drug molecule (active ingredient, AI). The drug substance poses serious safety issues and for that reason the standard available form of a diluted drug solution (10\%) in propylene glycol (PG) is first considered. After analyzing this base case, other solvents may be considered. The continuous phase of an ointment is by definition an oily mixture, in which PG is only slightly soluble. The product basic microstructure is thus an emulsion of the PG solution dispersed in a mixture of oily excipients. As a base case, we first consider a classical formulation of 4 excipients: white petrolatum, a standard oily excipient, anhydrous lanolin, also an oily ingredient but with a certain degree of hydrophilicity (oily aqueous excipient), paraffin wax, that works as a thickener, and sorbitan sesquioleate (Span 83), which is a good emulsifier for w/o emulsions. We thus have a total of 6 components: $1-\mathrm{drug}, 2-\mathrm{PG}, 3-$ lanolin, 4-petrolatum, 5-paraffin, and 6-Span 83.

Four quality factors were identified: (1) sustained release and delivery of the AI (transdermal transport followed by absorption into the blood circulation system); (2) homogeneity of the AI in the formulation (a given dose of ointment has consistently a constant amount of drug); (3) physical stability of the formulation; and (4) adequate consistency for application on skin. Each one of these factors were translated into performance metrics $p$ with physicochemical meaning and then these ones related to both product and process design variables, assuming as a starting point the above 


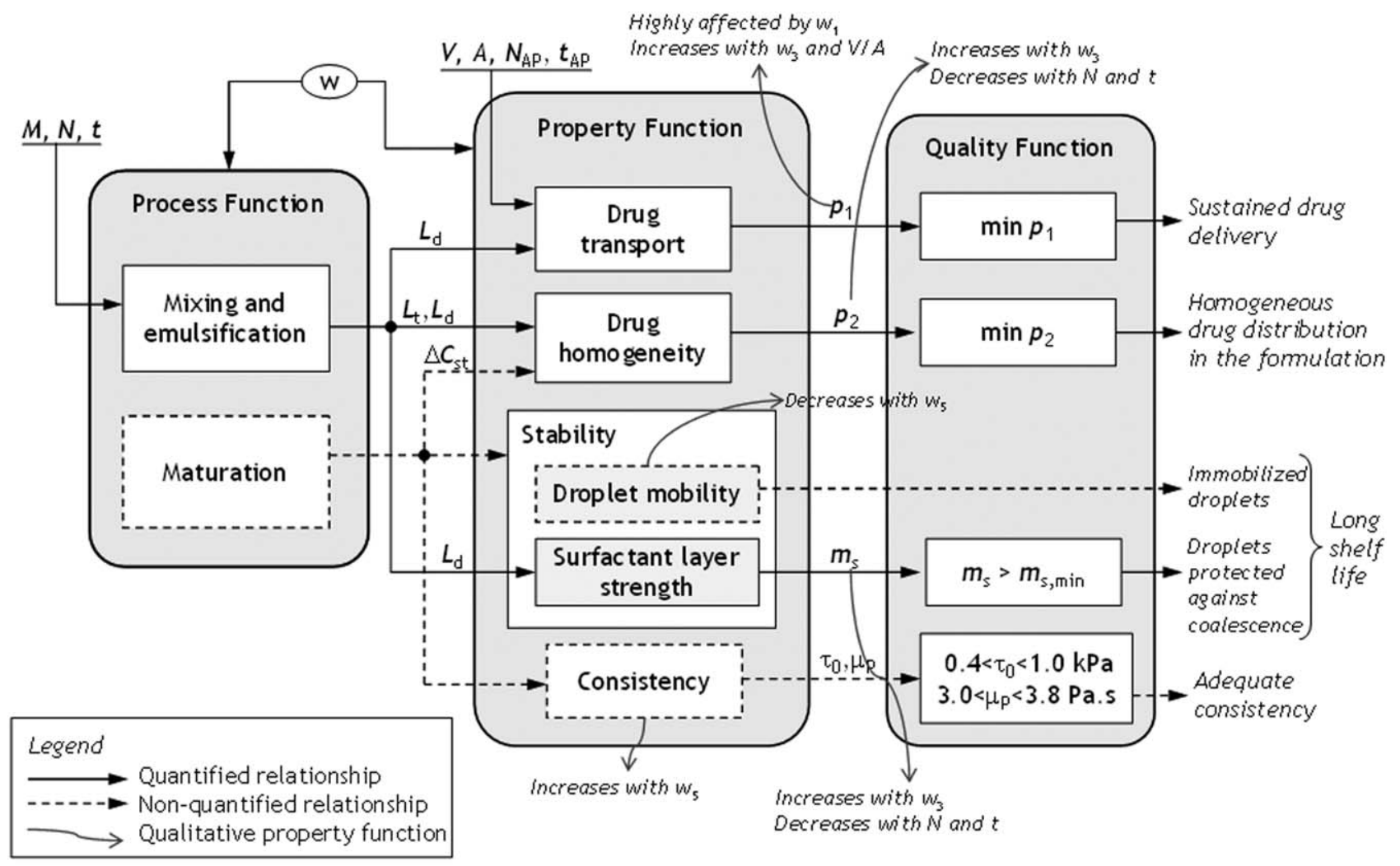

Variable sets

$d_{1}$ - mass fractions $w_{i}, i=1, \ldots, 6$.

$\boldsymbol{d}_{\mathbf{2}}$ - Batch size $M$.

$\mathbf{z}_{2}$ - stirrer speed in mixing tank $(N)$, mixing time at hot temperature $(t)$.

$\mathbf{x}_{\mathbf{1}}$ - droplet size $\left(L_{d}\right)$, segregation scale associated to turbulence $\left(L_{t}\right)$ and segregation intensity at that scale after maturation $\left(\Delta C_{s t}\right)$.

$\boldsymbol{z}_{\mathbf{1}}$ - ointment volume applied on skin $(V)$, area of application $(A)$, number of successive applications $\left(N_{A P}\right)$ and time between them $\left(t_{\text {AP }}\right)$.

Performance metrics $p$

$p_{1}$ - mean deviation of the temporal profile of drug concentration in plasma from a target value

$p_{2}$ - Homogeneity index (the smaller, the better)

$m_{\mathrm{s}}$ - Surfactant layer strength index (the larger, the better)

$\tau_{0}$ and $\mu_{p}$ - Yield stress and plastic viscosity (Bingham plastic model)

Figure 4. Structure, variables, and relationships of the ointment design problem according to the three functions model.

mentioned base formulation and a standard manufacturing process. Figure 4 shows the main relationships and variables organized according to our conceptual model of the three functions (quality, property, and process functions). Several physicochemical models are used, with different levels of detail and in some cases incorporating heuristic knowledge (e.g., known qualitative effect of a given component, typical concentration values). ${ }^{30}$ Some blocks only have a qualitative description. Here, we only provide a brief description of the drug transport model, based on which the performance metric $p_{1}$ is calculated. A detailed description of this transport model and discussion of predicted values is provided elsewhere. ${ }^{48}$ The fundamental mass-transfer equations are given in the Appendix.

After ointment application on skin, the drug molecule crosses several skin layers and reaches the blood circulation system. Here, drug transport and metabolism is fast enough so that a homogenous drug concentration in plasma $\left(C_{\mathrm{P}}\right)$ may be considered. This concentration varies with time, depending on the dynamics of transport across skin and of internal metabolism. A sustained drug delivery may then be quantified as the mean deviation of the temporal profile $C_{\mathrm{P}}(t)$ from a target value $C_{\mathrm{P}}{ }^{*}$, which should be as low as possible (see Figure 5 below). For a period $T$ after ointment application, one then defines the performance metric $p_{1}$ as

$$
p_{1}=\left(\frac{1}{T} \int_{0}^{T}\left(C_{\mathrm{P}}(t)-C_{\mathrm{P}}^{*}\right)^{2}\right)^{1 / 2}
$$

Profile $C_{\mathrm{P}}(t)$ is predicted from the above mentioned drug transport model comprising four compartments: ointment layer applied on skin (dispersed and continuous phases), two different skin layers and the blood circulation system. Drug transfer through these compartments is modeled as a series of interphase equilibria and diffusion processes. Some of the transport parameters are estimated as a function of ointment composition, in particular two drug partition coefficients: $K_{\text {cd }}$, referring to drug partition between continuous and dispersed phases of the ointment, and $K_{\mathrm{SC}, \mathrm{c}}$, between the outermost layer of the skin (Stratum Corneum, SC) and the ointment continuous phase. The model is a system of partial 


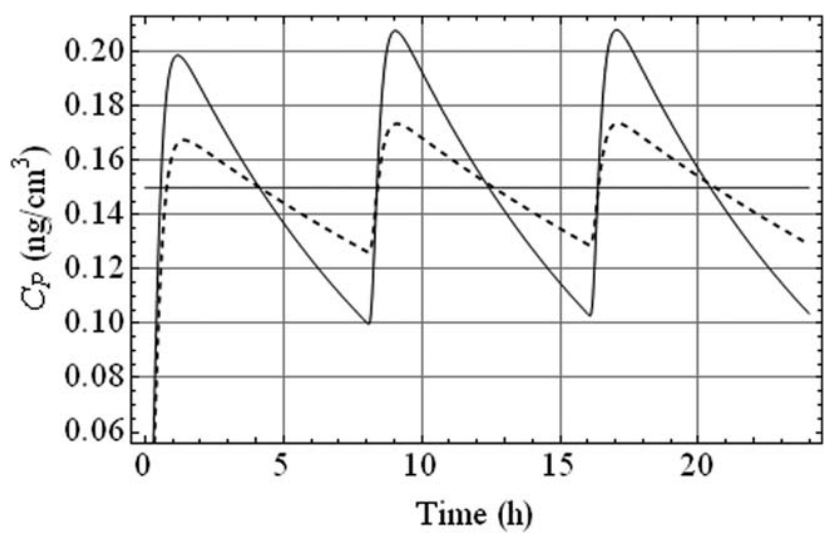

Figure 5. Predicted temporal profiles of drug concentration in plasma $\left(C_{\mathrm{P}}\right)$ after three consecutive ointment applications on skin: horizontal line-target concentration, dashed linebase ointment formulation (2\% drug, $18 \%$ PG, 14\% lanolin, 59\% petrolatum, 5\% paraffin, and $2 \%$ Span 83 ), full line-optimized formulation with new drug solvent $(3.7 \%$ drug, $21.3 \%$ DEG, $7.3 \%$ lanolin, $60.7 \%$ petrolatum, $5 \%$ paraffin, and $2 \%$ Span 83 ).

and ordinary differential equations that after spatial discretization results in a large linear system of ordinary differential equations. The integration of that system results in profile $C_{\mathrm{P}}(t)$ from which $p_{1}$ is then computed. All calculations are made in Mathematica. ${ }^{49}$

Using the nomenclature of the proposed conceptual model (Figure 2), the drug transport model has the following structure

$$
p_{1}=f\left(d_{1}, x_{1}, z_{1}, \theta_{1}, \theta_{3}\right)
$$

with the following sets of variables and parameters:

- Product design variables $d_{1}$ : vector $w$ of mass fractions of the ointment constituents;

- Product state variables $x_{1}$ : mean droplet size $L_{\mathrm{d}}$;

- Product use variables $z_{1}$ : ointment volume applied on skin $(V)$, area of application $(A)$, number of successive applications $\left(N_{\mathrm{AP}}\right)$, and time between them $\left(t_{\mathrm{AP}}\right)$;

- Constitutive parameters $\theta_{1}$ (estimated as a function of $w$ ): drug diffusivity in the ointment continuous phase $\left(D_{\mathrm{c}}\right)$, partition coefficients $K_{\mathrm{cd}}$ and $K_{\mathrm{SC}, \mathrm{c}}$.

- Surroundings parameters $\theta_{3}$ : drug diffusivity through the SC $\left(D_{2}\right)$, drug clearance from plasma, drug half-life time (among others).

Droplet size $L_{\mathrm{d}}$ is estimated within the process function block, using a simplified description of droplet breakup in a stirred tank. ${ }^{30}$ Partition coefficients $K_{\mathrm{cd}}$ and $K_{\mathrm{SC}, \mathrm{c}}$ are estimated based on regular solutions theory, known values of the solubility parameter $\delta$ for each component, and also empirical equations regarding partitioning into SC that take into account specific drug/SC interactions. ${ }^{48}$ Drug diffusivity in the ointment continuous is predicted from free volume theory with segmental motion. ${ }^{48}$ Table 4 shows some predicted values using as input a heuristic base design solution.

Back to the overall problem depicted in Figure 4, we now consider the optimal design of the ointment, keeping fixed the 6 ingredients of the base formulation and the manufacturing process design. The decisions are the mass fractions $w_{1}$ to $w_{6}$ and product use variables $V$ and $A\left(N_{\mathrm{AP}}\right.$
Table 4. Predictions of the Drug Transport Model for the Base Case

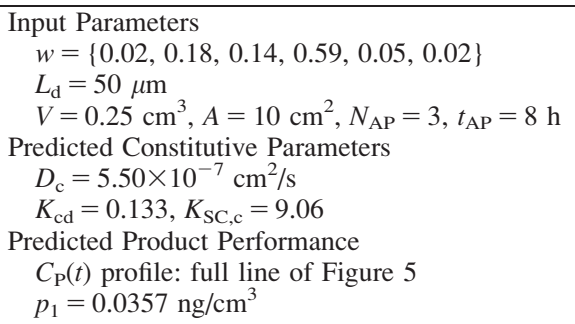

and $t_{\mathrm{AP}}$ are for now considered fixed). The adopted objective function is the sum of raw-material costs and penalty terms for high values of the performance indexes $p_{1}$ and $p_{2}$, and also high values of $V$ and $m$ (mass of drug in the dose $V$ ). The overall mathematical formulation integrates all the quantitative blocks of Figure 4 and may be represented as follows

$\min _{w, V, A}$ Total cost $=$ Raw-materials cost + Penalty terms $(\mathrm{EUR} / \mathrm{kg})$

s.t. Mixing and emulsification model : $\left\{L_{\mathrm{d}}, L_{\mathrm{t}}\right\}=f(w, N, t)$,

$$
\text { with } N=180 \mathrm{rpm}, t=1.5 \mathrm{~h}
$$

Drug transport model : $p_{1}=f\left(w, L_{\mathrm{d}}, V, A, N_{\mathrm{AP}}, t_{\mathrm{AP}}\right)$,

$$
\text { with } N_{\mathrm{AP}}=3, t_{\mathrm{AP}}=8 \mathrm{~h}
$$

Homogeneity index : $y_{2}=f\left(w, L_{\mathrm{d}}, L_{\mathrm{t}}\right)$

Index of surfactant layer strength : $m_{\mathrm{s}}=f\left(w, L_{\mathrm{d}}\right) \geq m_{\mathrm{s}, \min }$

Restrictions on composition :

$$
\begin{aligned}
& w_{1} /\left(w_{1}+w_{2}\right)=0.1, w_{5}=0.05, \\
& w_{4}=1-w_{1}-w_{2}-w_{3}-w_{4}-w_{5}, \\
& 0.01 \leq w_{1} \leq 0.03,0.05 \leq w_{3} \leq 0.3,0.005 \leq w_{6} \leq 0.1
\end{aligned}
$$

Limits on $V$ and $A: 0.1 \leq V \leq 1 \mathrm{~cm}^{3}, 8 \leq A \leq 20 \mathrm{~cm}^{2}$

This problem is solved explicitly considering 8 uncertain parameters, all with uniform distributions between lower and upper limits estimated based on available information: drug solubility parameter $\delta_{1}$ (which affects both $K_{\mathrm{cd}}$ and $K_{\mathrm{SC}, \mathrm{c}}$ ), $D_{\mathrm{c}}$, $D_{2}$, drug clearance from plasma (reflecting biological variability), two parameters regarding ointment manufacturing and also $V$ and $A$. The optimal solution found $(w=\{0.015,0.136$, $0213,0.555,0.050,0.031\}, V=0.45 \mathrm{~cm}^{3}$, and $A=10 \mathrm{~cm}^{2}$ ) has a total cost $39 \%$ lower than that for the base solution $\left(w=\{0.02,0.18,0.14,0.59,0.05,0.02\}, V=0.25 \mathrm{~cm}^{3}\right.$, and $A=10 \mathrm{~cm}^{2}$ ). The main gains are due to a more controlled release of the drug (and thus a lower value for $p_{1}$ ) and also some savings in raw-materials.

The above problem formulation and solution are only a first base case, of which main objective is to construct a workable modeling framework, as depicted in Figure 4. Based on this, other design questions may now be posed, such as substituting the drug solvent and/or some of the excipients, adding new specialized ingredients (e.g., skin permeation enhancers) or even changing the basic product structure (e.g., transdermal patch with ointment plus release rate controlling membrane). Some aspects of ingredients substitution are discussed in the following paragraphs.

The problem of ingredients substitution here addressed focus on the single objective of sustained drug release, which 
Table 5. Possible Candidates for Drug Solvent and Oily Aqueous Excipient

\begin{tabular}{clc}
\hline & \multicolumn{1}{c}{ Species } & $\delta\left[\left(\mathrm{J} / \mathrm{cm}^{3}\right)^{1 / 2}\right]^{50}$ \\
\hline Drug solvent & PG_Propylene glycol & 30.7 \\
& $\begin{array}{c}\text { (base case) } \\
\text { DEG-Diethylene glycol }\end{array}$ & 29.1 \\
& BG-Butylene glycol & 28.1 \\
(1,3-butanediol) & 18.1 \\
Oily aqueous & Lanolin (base case) & 20.0 \\
excipient & Lauryl alcohol & $19.2^{\mathrm{a}}$ \\
& Myristyl alcohol & $18.8^{\mathrm{a}}$ \\
\hline
\end{tabular}

${ }^{a}$ Estimated conciliating values from Ref. 51 with $\delta=20.0$ for lauryl alcohol.

may be formulated as to minimize $p_{1}$. Results from the base case above indicate that the key parameters affecting drug transport are the partition coefficients $K_{\mathrm{cd}}$ and $K_{\mathrm{SC}, \mathrm{c}}$ and that the key ingredients affecting these coefficients are the solvent $\mathrm{S}$ and the oily aqueous excipient E3. It is then convenient to write the performance index $p_{1}$ as a function of the solubility parameters of these two key species, $\delta_{\mathrm{s}}$ and $\delta_{\mathrm{E} 3}$, and also mass fractions $w$ for all species: $p_{1}=f\left(w, \delta_{\mathrm{s}}, \delta_{\mathrm{E} 3}\right)$. Given this property function, the selection of new ingredients $S$ and E3 is equated in two stages. First, we look for optimum values for the solubility parameters $\delta_{\mathrm{s}}$ and $\delta_{\mathrm{E} 3}$

$$
\begin{gathered}
\min _{\delta_{\mathrm{S}}, \delta_{\mathrm{E} 3}, w} p_{1} \\
\text { s.t. } p_{1}=f\left(\delta_{\mathrm{S}}, \delta_{\mathrm{E} 3}, w\right) \\
g\left(\delta_{\mathrm{S}}, \delta_{\mathrm{E} 3}, w\right) \leq 0
\end{gathered}
$$

Note that this problem may be seen as a particular case of formulation (8) above, as we seek for optimum values for the constitutive parameters $\delta_{\mathrm{s}}$ and $\delta_{\mathrm{E} 3}$, independently of the molecular species $\mathrm{S}$ and E3. The solution found is $\delta_{\mathrm{S}}=29.7$ (lower bound) and $\delta_{\mathrm{E} 3}=20.4\left(\mathrm{~J} / \mathrm{cm}^{3}\right)^{1 / 2}$. The second stage of the problem is then to look for molecular species having $\delta$ values close to these ones. Consulting a database with $\delta$ values and also using additional criteria (miscibility with ointment components, viscosity), the candidates in Table 5 are selected (the table also shows the base case, where $\mathrm{S}=\mathrm{PG}$ and E3 = lanolin). A more exploratory search could be made using a group contribution method to estimate $\delta$ values and a set of molecular groups covering a plausible larger chemical domain (e.g., fatty alcohols, fatty acids, and their esters).

Overall, there are 12 pairs $\{\mathrm{S}, \mathrm{E} 3\}$. For each one, the composition $w$ that minimizes $p_{1}$ is calculated (with $V$ and $A$ fixed at the base values). The base solution (pair PG/lanolin, $w=\{0.02,0.18,0.14,0.59,0.05,0.02\})$ has a performance $p_{1}=0.0357 \mathrm{ng} / \mathrm{cm}^{3}$. Nine of the 12 pairs, after optimizing $w$, have a significantly better performance with $p_{1}$ around 0.022 $\mathrm{ng} / \mathrm{cm}^{3}$, and are thus selected for further analysis, including experimental tests. Using some additional criteria, the pair DEG/lanolin seems to be the most promising (optimized mass fractions $w_{1}$ to $w_{4}$ equals to $0.037,0.213,0.073$, and $0.607 ; w_{5}$ and $w_{6}$ fixed at base values). Figure 5 compares the predicted profiles of drug concentration in plasma for this solution and the base case, clearly showing the significant improvement in terms of a more sustained drug delivery. It should be noted that the solutions here calculated are partial solutions in the sense that they are focused on a single objective (minimize $p_{1}$ ), and thus significant adjustments may be needed to attain a reasonable equilibrium between all quality factors.

\section{Conclusions}

We have proposed a simple and schematic conceptual model for chemical product design, interlinking three central design functions (quality function, property function, and process function) through five design domains (product quality, performance, use conditions, composition and structure, and manufacturing process). The model may function in practice as a basis to organize information, identify important variables and relationships, and set up mathematical formulations of particular subproblems. In particular, we have discussed the construction of optimization formulations on top of the proposed conceptual framework and some key difficulties and challenges to apply systematic optimizationbased tools to the design of more complex products, namely microstructured formulated products. Two simple illustrative examples and a more detailed case study of a pharmaceutical formulation were presented, illustrating how the conceptual model functions as a working platform and how optimization concepts and tools may assist the solution of some subproblems.

\section{Literature Cited}

1. Douglas JM. Conceptual Design of Chemical Processes. New York: McGraw-Hill, 1988.

2. Cussler EL, Moggridge GD. Chemical Product Design. Cambridge: Cambridge University Press, 2001.

3. Cussler EL, Moggridge GD. Chemical Product Design, 2nd ed. Cambridge: Cambridge University Press, 2011.

4. Ulrich KT, Eppinger SD. Product Design and Development, 3rd ed. New York: McGraw Hill, 2003.

5. Ng KM, Gani R, Dam-Johansen K. Product development-what to make and how to make. In: Ng KM, Gani R, Dam-Johansen K, editors. Chemical Product Design: Toward a Perspective Through Case Studies. Amsterdam: Elsevier, 2007:473-489.

6. Costa R, Moggridge GD, Saraiva PM. Chemical product engineering: an emerging paradigm within chemical engineering. AIChE J. 2006;52(6):1976-1986.

7. Cussler EL, Wei J. Chemical product engineering. AIChE J. 2003; 49(5):1072-1075.

8. Favre E, Marchal-Heusler L, Kind M. Chemical product engineering: research and educational challenges. Chem Eng Res Des. 2002; 80(A1):65-74.

9. Villadsen J. Putting structure into chemical engineering-proceedings of an industry/university conference. Chem Eng Sci. 1997; 52(17):2857-2864.

10. Voncken RM, Broekhuis AA, Heeres HJ, Jonker GH. The many facets of product technology. Chem Eng Res Des. 2004;82(A11):14111424.

11. Wesselingh JA. Structuring of products and education of product engineers. Powder Technol. 2001;119(1):2-8.

12. Westerberg AW, Subrahmanian E. Product design. Comput Chem Eng. 2000;24(2-7):959-966.

13. Wintermantel K. Process and product engineering-achievements, present and future challenges. Chem Eng Sci. 1999;54:1601-1620.

14. Wesselingh JA, Kiil S, Vigild ME. Design and Development of Biological, Chemical, Food and Pharmaceutical Products. Chichester, England: Wiley, 2007.

15. Wei J. Product Engineering: Molecular Structure and Properties. Oxford: Oxford University Press, 2007.

16. Wibowo C, Ng KM. Product-centered processing: manufacturing of chemical-based consumer products. AIChE J. 2002;48(6):1212-1230.

17. Seville JPK, Fryer PJ, Norton IT. Formulation of structured chemical products. In: Bröckel U, Meier W, Wagner G, editors. Product Design and Engineering: Best Practices, Vol. 2. Weinheim: WileyVCH, 2007:473-489.

18. Hill M. Product and process design for structured products. AIChE J. 2004;50(8):1656-1661.

19. Hill M. Chemical product engineering-the third paradigm. Comput Chem Eng. 2009;33(5):947-953.

20. Cordiner JL. Challenges for the PSE community in formulations. Comput Chem Eng. 2004;29:83-92. 
21. Schubert H, Engel R. Product and formulation engineering of emulsions. Chem Eng Res Des. 2004;82(A9):1137-1143.

22. Schuchmann HP, Schubert H. Product design in food industry using the example of emulsification. Eng Life Sci. 2003;3(2):67-76.

23. Wibowo C, Ng KM. Product-oriented process synthesis and development: creams and pastes. AIChE J. 2001;47(12):2746-2767.

24. Fung KY, Ng KM. Product-centered processing: pharmaceutical tablets and capsules. AIChE J. 2003;49(5):1193-1215.

25. Fung $\mathrm{H}$, Wibowo $\mathrm{C}, \mathrm{Ng} \mathrm{KM}$. Product-centered process synthesis and development: detergents. In: Ng KM, Gani R, Dam-Johansen K, editors. Chemical Product Design: Toward a Perspective Through Case Studies. Amsterdam: Elsevier; 2007:239-274.

26. Achenie LEK, Gani R, Venkatasubramanian V, editors. ComputerAided Chemical Engineering, Vol. 12. Computer Aided Molecular Design: Theory and Practice. Amsterdam: Elsevier, 2002.

27. Gani R. Computer-aided methods and tools for chemical product design. Chem Eng Res Des. 2004;82(A11):1494-1504.

28. Gani R. Chemical product design: challenges and opportunities. Comput Chem Eng. 2004;28:2441-2457.

29. Bernardo FP, Saraiva PM. Integrated Process and Product Design Optimization: a Cosmetic Emulsion Application. In: Puigjaner L, Espuña A, eds. ESCAPE-15, Computer-Aided Chemical Engineering, Vol. 20B. Amsterdam: Elsevier; 2005:1507-1512.

30. Bernardo FP. Contributos para Projecto Sistemático e Integrado de Produtos e Processos Químicos [PhD thesis]. Coimbra: Chemical Engineering, Universidade de Coimbra, 2010.

31. Cisternas LA. Nature of chemical products. In: Ng KM, Gani R, Dam-Johansen K, editors. Chemical Product Design: Toward a Perspective through Case Studies. Amsterdam: Elsevier, 2007:459-472.

32. Cisternas LA, Gálvez ED. Principles for chemical products design. In: Marquardt W, Pantelides C, editors. ESCAPE-16 + PSE 2006, Computer-Aided Chemical Engineering, Vol. 21. Amsterdam: Elsevier, 2006:1107-1112.

33. Hadgraft J. Skin, the final frontier. Int J Pharm. 2001;224:1-18.

34. Cussler EL, Wagner A, Marchal-Heussler L. Designing chemical products requires more knowledge of perception. AIChE J. 2010; 56(2):283-288.

35. Phadke MS. Quality Engineering Using Robust Design. New Jersey: Prentice Hall, 1989.

36. Bagajewicz MJ. On the role of microeconornics, planning, and finances in product design. AIChE J. 2007;53(12):3155-3170.

37. Smith BV, Ierapetritou M. Framework for consumer-integrated optimal product design. Ind Eng Chem Res. 2009;48(18):8566-8574.

38. Biegler LT, Grossmann IE, Westerberg AW. Systematic methods of chemical process design. London: Prentice-Hall, 1997.

39. Eden MR, Jørgensen SB, Gani R, El-Halwagi MM. A novel framework for simultaneous separation process and product design. Chem Eng Process. 2004;43:595-608.

40. GAMS - On-line Documentation. Available at: http://www.gams.com/docs/document.htm. Accessed on May, 2014.

41. Machado DMJ, Neves FJM, Mendes FP, Araujo PP, Duarte BPM, Oliveira NMC. Systematic selection of extraction solvents in the aromatics production. In: Jezowski J, Thullie J, editors. ESCAPE-19, Computer-Aided Chemical Engineering, Vol. 26. Amsterdam: Elsevier, 2009:75-80.

42. Tsai J-F, Lin M-H, Hu Y-C. Finding multiple solutions to general integer linear programs. Eur J Oper Res. 2008;184(2):802-809.

43. Pistikopoulos EN. Uncertainty in process design and operations. Comput Chem Eng. 1995;19:S553-S563.

44. Bernardo FP, Pistikopoulos EN, Saraiva PM. Quality costs and robustness criteria in chemical process design optimization. Comput Chem Eng. 2001;25:27-40.

45. Bernardo FP, Saraiva PM. Value of information analysis in product/ process design. In: Barbosa-Póvoa P, Matos H, editors. ESCAPE-14, Computer-Aided Chemical Engineering, Vol. 18. Amsterdam: Elsevier, 2004:151-156.

46. Bernardo FP, Saraiva PM, Pistikopoulos EN. Inclusion of information costs in process design optimization under uncertainty. Comput Chem Eng. 2000;24:1695-1701.

47. Mata VG, Gomes PB, Rodrigues AE. Engineering perfumes. AIChE J. 2005;51(10):2834-2852.

48. Bernardo FP, Saraiva PM. A theoretical model for transdermal drug delivery from emulsions and its dependence upon formulation. J Pharm Sci. 2008;97(9):3781-3809.

49. .Wolfram MathWorld. Available at: http://mathworld.wolfram.com. Accessed on January, 2014.
50. Barton AFM. Handbook of Solubility Parameters and Other Cohesion Parameters, 2nd ed. Boca Raton: CRC Press, 1991.

51. Vaughan CD. Using solubility parameters in cosmetics formulation. J Soc Cosmet Chem. 1985;36:319-333.

\section{Appendix: Mass-Transfer Model}

The model here provided is for the transport of a single component (drug) from an emulsion applied on skin (compartment 1), then across two skin layers in series (stratum corneumcompartment 2, and viable epidermis-compartment 3), and finally with absorption into the blood circulation system (compartment 4). Transport is considered in a single direction $z$, perpendicular to skin surface.

Nomenclature: $C$ is drug molar concentration, $t$ is time, $d$ is emulsion dispersed phase, $c$ is emulsion continuous phase, and numbers 1-4 refer to compartments $1-4$. Other symbols are defined when used.

Compartment 1. Layer of emulsion with thickness $L_{1}$ applied on skin over area $A$.

$$
\begin{gathered}
\frac{\partial C_{\mathrm{d}}}{\partial t}=-\frac{k_{\mathrm{i}} A_{\mathrm{i}}}{V_{\mathrm{d}}}\left(C_{\mathrm{ce}}-C_{\mathrm{c}}\right) \\
(1-\phi) \frac{\partial C_{\mathrm{c}}}{\partial t}=D_{1} \frac{\partial^{2} C_{\mathrm{c}}}{\partial z^{2}}+\frac{k_{\mathrm{i}} A_{\mathrm{i}}}{V}\left(C_{\mathrm{ce}}-C_{\mathrm{c}}\right)
\end{gathered}
$$

$A_{\mathrm{i}}$ is the total interfacial area, $V_{\mathrm{d}}$ the dispersed phase volume, $V$ the total emulsion volume $\left(V=A \times L_{1}\right)$, and $\phi$ the dispersed phase volume fraction $\left(\phi=V_{\mathrm{d}} / V\right)$. The interfacial area $A_{\mathrm{i}}$ is given by $A_{\mathrm{i}} / V=6 \phi / L_{\mathrm{d}}$, with $L_{\mathrm{d}}$ being the Sauter mean diameter. $D_{1}$ is the effective diffusion coefficient in the emulsion. $C_{\mathrm{ce}}$ is an equilibrium concentration with $C_{\mathrm{d}}$, and thus $C_{\mathrm{d}}=C_{\mathrm{ce}} / K_{\mathrm{cd}} . \quad K_{\mathrm{cd}}$ is the drug partition coefficient between continuous and dispersed phases of the emulsion. $k_{\mathrm{i}}$ is a global interfacial mass-transfer coefficient.

Initial and boundary conditions

$$
\begin{gathered}
t=0,-L_{1} \leq z \leq 0: C_{\mathrm{c}}=C_{\mathrm{ce}}=\frac{K_{\mathrm{cd}} C_{0}}{\phi+K_{\mathrm{cd}}(1-\phi)} \\
z=-L_{1}, t>0: \frac{\partial C_{c}}{\partial z}=0 \\
z=0, t>0: D_{1} \frac{\partial C_{\mathrm{c}}}{\partial z}=D_{2} \frac{\partial C_{2}}{\partial z}
\end{gathered}
$$

$C_{0}$ is the initial total concentration (moles of drug per unit volume of emulsion).

Compartment 2. SC with thickness $L_{2}$.

$$
\begin{gathered}
\frac{\partial C_{2}}{\partial t}=D_{2} \frac{\partial^{2} C_{2}}{\partial z^{2}} \\
t=0,0 \leq z \leq L_{2}: C_{2}=C_{20}(z) \\
z=0, t>0: C_{2}=K_{2 \mathrm{c}} C_{\mathrm{c}} \\
z=L_{2}, t>0:-D_{2} \frac{\partial C_{2}}{\partial z}=D_{3} \frac{C_{3}}{L_{3}}
\end{gathered}
$$

$D_{2}$ is the effective diffusion coefficient through the SC. $K_{2 \mathrm{c}}$ is the drug partition coefficient between the $\mathrm{SC}$ and the emulsion continuous phase $\left(K_{\mathrm{SC}, \mathrm{c}}\right.$ in the main text). $D_{3}$ is the effective diffusion in the viable epidermis (VE). $K_{32}$ is the drug partition coefficient between the VE and the SC.

Compartment 3. Viable epidermis (VE).

Pseudosteady state is considered. $C_{3}$ is the concentration at the inner boundary. The concentration at the outer boundary is considered nil. 


$$
C_{3}=\left.K_{32} C_{2}\right|_{z=L_{2}}
$$

Compartment 4. Blood circulation system. Modeled as a homogenous compartment.

$$
V_{4} \frac{d C_{4}}{d t}=D_{3} \frac{\left.K_{32} C_{2}\right|_{z=L_{2}}}{L_{3}} A-k_{4} V_{4} C_{4}
$$

$C_{4}$ is the drug concentration in plasma $\left(C_{P}\right.$ in the main text). $k_{4}$ is the first-order kinetic constant of drug elimination from plasma. $V_{4}$ is the apparent volume of drug distribution in the body. Alternative parameters are half-life time $t_{1 / 2}$ and clearance CL. The following relationships hold: $k_{4}=\ln (2) / t_{1 / 2}$ and $\mathrm{CL}=k_{4} V_{4}$.

Manuscript received July 30, 2014, and revision received Nov. 7, 2014. 